\title{
Debate
}

\section{Let's not opt out: kidney donation and transplantation}

\section{Robert A Sells Renal Transplant Unit, Royal Liverpool Hospital, Liverpool}

In his long and well-argued paper in the fournal of medical ethics ${ }^{1}$ lawyer Ian Kennedy persuasively and attractively deploys arguments in favour of changing the Human Tissue $\mathrm{Act}^{2}$ from the present two tier form to an 'opting out' system. The foundations from which he launches his arguments appear at first sight to be impregnable; firstly, there is the ambiguity of wording in the Act which for many years has tantalised lawyers and doctors concerning the interpretation of such terms as 'reasonable' and 'practicable'; secondly, the fact that the law is really a compromise, containing an 'opting in' clause (allowing organs to be removed if the donor has given permission thereto during his life) but also giving the option to the relatives to object if no permission has been given. This compromise seeks to avoid conflict with groups opposed to transplantation, and may give the wishes of the spouse and relatives priority over the interests of patients dying with renal failure; his third, and most contentious, claim is that an 'opting out' principle would significantly improve the supply of donor organs for people with renal failure who need them.

I do not intend to take issue with Kennedy on the legal analysis of the law which he has represented, but I do wish to put an opposite view: that I believe the law should not be changed to an 'opting out' principle. The reason is that, although changes might seem legally desirable, the present law is in fact sufficiently unrestrictive to allow legally sanctioned removal of organs from people who die in hospital; and more important, the supply of organs for transplantation would not be significantly increased by changing the law to an 'opting out' principle.

To develop this argument in a short article it will be helpful to describe the participants in the act of transplantation, their medical and other professional representatives, their roles and their rights. The rules which are now generally recognised concerning transplantation will be described, and the relative unrestrictiveness of the law in the United Kingdom will, hopefully, be demonstrated.

\section{The kidney donor}

The donor is a person who has been admitted to $\vec{\omega}$

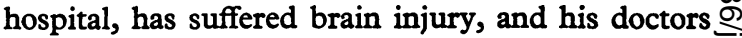
have certified death. Because of the technical $\bar{B}$ requirements of kidney transplantation, patients or who suffer permanent cardiac arrest before arriving :at hospital, or who have kidney disease or cancer $\vec{\sigma}$ cannot be considered as suitable donors; the com- $O$

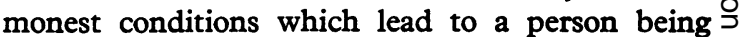
suitable as a kidney donor are those which lead to brain death with persistent survival of the heart and $\Phi$ circulation with consequent normal function of the $\Phi$ other vital organs such as the kidneys and liver. $\frac{3}{0}$ Such patients are maintained in a state of physio- $\mathbb{D}$ logical stability by artificial ventilation. By the time $\vec{\theta}$ that the transplant surgeon is brought in by the donor's doctors, the decision has already been made to switch off the ventilator, since death is certain.

\section{THE DONOR'S RELATIVES}

Since the donor is almost always maintained on a $\stackrel{\circ}{\circ}$ ventilator for some hours or days before death, $\propto$ there is nearly always time for the relatives to be $\overrightarrow{\overrightarrow{0}}$ contacted by the hospital before death, and there- 3 fore they will usually be in attendance at the time of death. The donor's relatives in the majority of cases have a considerable responsibility for the

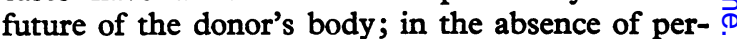
mission given in life by the donor for the removal of organs, they may object to the organs being removed.

THE TEAM OF DOCTORS LOOKING AFTER THE DONOR

The team will have made every possible effort to 옥 sustain the patient before death has been diagnosed $\rightarrow$ by emergency treatment of injuries, maintaining the blood pressure, using blood and fluid transfusions, $N$ and taking other appropriate remedies. By the time the patient is put on artificial ventilation, the ad- 0 mitting doctor will normally have notified the con- $\omega$ sultant in charge of the case and the expert services of an anaesthetist or neuro-surgeon may well have been enlisted. The donor's doctor fulfils a difficult $\overparen{D}$ and dual role - up to the time of death every effort ?has been directed to saving the patient's life, but $\underline{T}$ after the time of death then the decision to consider $\frac{\vec{D}}{\mathbb{D}}$ the patient as a donor involves a change of direction; $\frac{\rho}{1}$ from that moment onwards, the doctors are taking $\triangle$ the decision on behalf of another patient who is unknown to them. This change of clinical direction $ᄋ$ and responsibility does pose difficulties for many 
doctors, particularly when they are faced with the failure of their treatment after a difficult and arduous period before their own patient's demise. Possibly this is a reason why some doctors do not refer patients as donors.

\section{THE AREA HEALTH AUTHORITY}

The Authority is technically and legally the person in charge of the body until it is claimed by the executors. A recognised representative of the Health Authority (who may be an administrator or a deputed senior nurse of doctor), may authorise the removal of organs after the necessary legal criteria have been fulfilled.

\section{THE CORONER}

In cases where death has arisen as a result of injury or unnatural causes, the Coroner is the custodian of forensic evidence; every coroner's case that is being considered as a donor must be notified to the coroner's office, and permission sought for organ donation. If permission is not given then organ donation must not take place. If the case is not a coroner's case, then the coroner need not be approached. The coroner also has a duty to see that death has occurred before the organs are removed, and at the inquest it will be necessary for accurate documentary evidence of the sequence of events prior to organ removal to be provided to substantiate this fact. The liberality or restrictiveness of interpretation of the coroner's rules applied to organ donation varies widely with the opinions held by different coroners.

\section{The recipient}

The recipient of the donor's kidney is a patient usually at another hospital (maybe in another city or country) who has no kidney function, and who is being maintained alive on artificial kidney machine treatment. The patient is usually one of a group (up to 200 ) whose therapy is managed by a particular unit. In the United Kingdom there are 32 such dialysis units spread throughout the regions. Those dialysis patients who are fit enough, and willing to have a transplant, enrol on the regional transplant unit waiting list, which will be updated as new cases are referred. At the last count (March 1979) there were 1300 people on artificial kidney machines awaiting a cadaver renal transplant ${ }^{3}$. Details of the patient's blood group and tissue type are kept at a Central Registry at Southmead Hospital, Bristol UK Transplants which has links with similar computerised recipient networks in Denmark, Holland and France.

\section{THE DOCTORS}

The recipient's doctors most immediately concerned with his welfare are physicians expert in dialysis; all dialysis physicians have access to Regional Transplant Units of which there are approximately
22 in the United Kingdom. It is the transplant surgeon and his team, based on the transplant unit, who have to go out to district hospitals and conduct e $^{\text {? }}$ propaganda and educational campaigns to persuade their colleagues who look after brain dead patients of the need for cadaveric kidneys, and to maintain an awareness of this need in district hospitals to which donors may be referred when suitable cases are admitted. In the United Kingdom the transplan surgeon removes the donor kidneys when death has been certified and the legal and ethical criteria have $\overrightarrow{0}$ been satisfied.

\section{The rule books}

THE HUMAN TISSUE ACT (196I) ${ }^{2}$

As Mr Kennedy points out ${ }^{1}$, when Parliament was faced with the job of revising the law to accom-? modate organ transplantation in 196I, it chose a two-tier approach rather than adopting a unitaryo legislation for organ donation such as 'contracting out' alone or 'contracting in' alone. Thus in sections $I$, part one, there is a 'contracting in' arrangement whereby the deceased's request that his organs be removed after death may be complied with; at the discretion of the person lawfully in charge of the body, the surgeon may remove the organs without reference to the relatives. Section I, part two, of the Act covers those circumstances (the majority of cases) where the deceased has not made such कै request; in these cases, the person lawfully in possession of the body may 'authorise the removat of any part from the body if, having made such reasonable enquiry as may be practicable, he has no? reason to believe that the deceased had expressed anp objection during life', or 'that the surviving spouse or any surviving relative of the deceased, objects too the body being so dealt with'. To the lawyer, such? equivocal language is infuriating, and professionally wrong. The lawyers' aggravation about the sorryo state of the law is heightened (as exemplified in $\mathrm{Mr}^{2}$ Kennedy's article) by the apparent failure to pro윽 vide, in law, any sanctions which may be brough against the doctor who does not comply with the Act when removing organs for transplantation. Tor the transplant surgeon whose interpretation of the law will be on a basis of common sense as well aso legal accuracy, phrases such as 'reasonable enquiryw as may be practicable' are easier to understand and? work with, although he will be no better able too define these terms than the lawyer. The doctor knows, however, that in the context of transplant-ation, it would not be practicable to conduct enquiries for, say, one month concerning the views of the relatives of the deceased, before allowing? a transplant surgeon to remove organs; such delay would be incompatible with the maintenance of healthy organs for transplantation, and then maintenance of the patient on a ventilator for sucho 
a prolonged period of time purely to fulfil legal criteria would be objectionable and unacceptable to the doctors looking after that patient. At the other extreme, where there is a possible risk of too hasty a process of enquiry, most doctors would agree that it is not enough to say, in a case where organs must be removed very soon after death, that no enquiry is practicable. Interpretation of this part of the Act must involve a compromise between these two extremes, and most health authority representatives would not feel that enquiries made had been reasonable and practicable until proper efforts to inform the relatives and bring them to hospital had been exhausted using the telephone, approaches to neighbours, and enlisting the help of the police.

\section{A DHSS GUIDANCE CIRCULAR}

In 1975, the Department of Health and Social Security produced a Guidance Circular to NHS authorities on the Human Tissue Act $196 \mathrm{I}^{4}$. This valuable document, which was circulated to Area Health Authorities, and presumably was read by many people in charge of bodies in NHS hospitals, has also been of great assistance in interpreting the law to transplant surgeons and clinicians looking after donors. It is an exhaustive but commonsense account of the law presented by legal representatives of the DHSS which presents in some depth the interpretation of the law in various different circumstances which confront clinicians and administrators.

\section{THE MCLENNAN REPORT ${ }^{5}$}

Advice from an advisory group on transplantation problems on the question of amending the Human Tissue Act 1961 published in 1969, comprehensively surveyed the problems posed by transplantation, and gave sensible and encouraging advice to the Health Ministers at the time. The report made several important points: It highlighted the need to separate the management of a seriously ill patient from consideration of organ donation before death had taken place. From this important point emerged the crucial recommendation that 'the doctor clinically responsible for the care of the potential donor will always be different from the doctor clinically responsible for a prospective recipient'. Although this is not a statutory recommendation it is a suggestion with such ethical force as to be an indispensable component of every transplant team's policy, and every hospital's policy when dealing with donors. The report unreservedly supported cadaveric transplantation and suggested various ways in which increased co-operation from the profession could be elicited to supply more donors. It also supported a 'contracting in' principle.

\section{THE DIAGNOSIS OF BRAIN DEATH ${ }^{6}$}

This report was a recent addition to the rules concerning the diagnosis of death. Although the problem of diagnosing brain death has been with the profession ever since the first artificial respirato was invented, there had been some disquiet ex pressed that the advent of transplantation with it attendant need to remove organs from a recently deceased person in as good a state as possible, might generate pressure on the doctors looking after $\overline{\bar{\omega}}$ potential donor which might lead to the premature removal of organs before certain death had occurred The issuing of the brain death criteria in 1976 if the British medical journal and Lancet by a group $\overrightarrow{0} \vec{\Phi}$ experts drawn from the combined Colleges of Surgeons and Physicians of the United Kingdorff and Ireland, and which went unchallenged in the medical press by the profession, has established $\mathbb{Q}$ clear, independent and widely accepted list of clinical signs which, if applied in the correct way and in the correct patient, enable an incontros vertible diagnosis of brain death to be made. This bringing together of the criteria has, in the author's. experience, not only regularised a previously variable practice, but has on several occasions made thø reality of death easier for the relatives to grasp when they were assured that documented criteria had bee used to diagnose it.

The goal of successful, decorous and legal orgab donation is achieved by paying due regard to the legal and ethical rules outlined above, and more importantly, by treating the participants in the affair with respect and compassion. A well thoughi out plan acceptable to doctors and administrators is an absolute essential to avoid the pitfalls which await the unwary and the inexperienced in this field?.

\section{A plan for kidney donation}

When a patient in hospital suffers brain damage, th doctor looking after him will interview the patient's relatives (who are present in the majority of cases and tell them of the hopeless situation. If the doctop is aware of the shortage of kidneys and of the suit ability of the patient as a donor, he will contact the transplant team by telephone. While the transplants surgeon is on his way to the hospital, the doctors: looking after the potential donor may well choose this time available to record in the notes the diagnostic criteria by which they have determine必 brain death. When the transplant surgeon arrivesş his first act is to satisfy himself that death has occurred (this is a mandatory requirement of the Human Tissue Act, 196I). By this time a bloo sample will have been taken from the patient for tissue typing at the local tissue typing laboratory, so that the best recipient of the donor's kidneys can be्ष identified and prepared. After examining the bodye which will still be connected to a ventilator and wil still have a heart beat, the transplant surgeon wil then ascertain whether or not the patient was carrying a kidney donor card or other means od 
expressing willingness to donate organs after death. At the time of publication, it appears that the majority of patients do not carry kidney donor cards. So in accordance with the law, every reasonable and practicable attempt must be made to identify the relatives, and to see whether they object to the removal of organs. Since most relatives can usually be found and will almost invariably be within reach of the hospital, if not in the hospital at the time the transplant surgeon arrives, the difficulties posed by the phrase 'having made such reasonable enquiry as may be practicable' are therefore largely removed. The next reasonable and practical step is obviously to interview them and ascertain if they object to the removal of organs. The transplant surgeon must check with the doctor that the relatives are aware of the death of the patient before he asks whether they object. It is also wise to have a witness present (usually a senior nurse or a member of the team looking after the donor) and verbal consent may be recorded in the notes by the transplant surgeon and signed by the witness. There is no statutory requirement for the relatives to sign a document stating their non-objection, nor is it thought justifiable or humane to ask them to do this.

Although the notion of interviewing patients at such a difficult time in their lives is perhaps objectionable, it is most reassuring to find that the majority of patients' relatives do not in fact object to organ removal for transplantation, and quickly see the benefit, which can be derived from an otherwise totally tragic situation, to another individual. In our experience in Merseyside 94 per cent of relatives do not object; this high rate of acceptance has been achieved by a member of the transplant team asking the relatives, and it seems that when the donor doctors interview the relatives, the refusal rate may be higher. There are also indications from letters received from relatives after organ donation has taken place, that although the interview and the need to make a decision may be acutely painful, the comfort and satisfaction to the family derived from knowing what has happened, may in the long term be beneficial. In those very few cases where the relatives cannot be found in spite of the measures recommended above, the person in charge of the body must review the situation with the doctors involved, and decide whether organ removal may proceed.

With the Coroner's consent and the approval of the representative in charge of the body, the donor's corpse is taken to the operating theatre, the respiration and circulation being maintained, and the kidneys are surgically removed. Each is wrapped separately in sterile bags, placed in an ice box, and transported to the hospital where the recipient, chosen on the basis of the donor's tissue type, is prepared for the transplant operation. Kidneys removed while the heart is still beating, or within fifteen minutes of its arrest, may survive storage for periods of up to 24 hours, but longer periods of storage require more sophisticated preservation techniques. It is now routine for kidneys to be moved over very long distances, often between Continents to achieve the best tissue match between donor and recipient, and hopefully thereby to achieve the best result. It is obviously good practice for the transplant team to inform the doctors and nurses who looked after the donor what the outcome of the transplant operation was. This simple act of good manners will gratify curiosity, enhance the image of the transplant team, and probably result in more donors being referred.

It will be observed that there are many factors in transplantation other than the law which influence the supply of organ grafts, and the important ones are outlined in this article. Not all of them are problematical in that they do not impede significantly the process of legal organ donation. The structure of the Human Tissue Act belongs to this nonproblematical category; in order to support a radical change in the law to an opting-out system, as Kennedy and some parliamentarians have suggested, one would have to provide evidence firstly that kidneys have not been donated because relatives could not be brought to hospital in time for interview before the death of the patient, or that authorities were reluctant to allow donation in the absence of the relatives given though 'reasonable enquiry as may be practicable' had been instituted, and secondly that significant numbers of relatives objected to organs being removed. From the material presented here it is clear that neither of these factors seriously impairs the supply of organs. It follows that the law should not be changed to a contracting-out system, although its wording may well need tidying up. In addition to the medical evidence for this view presented here, there is also well-publicised objection (in other spheres) to the presumption that 'unless you have recorded your objection during life, it shall be assumed that you do not object to the removal of your organs after death'. A debate on law reform which contained this and other more contentious ingredients could attract opprobrium to transplantation and related fields, and the recent increase in the donor supply (albeit slow) could suffer a set-back as a result. Such an outcome is greatly to be feared, particularly as it has taken several years to achieve even our present modest supply of kidney grafts (which total approximately one third of those required per year).

The single most important impediment to an adequate supply of grafts is to be found within the profession itself. Many doctors are still reluctant to refer dead patients with functioning kidneys as organ donors. To engender the same degree of initiative in those doctors who care for brain dead patients as exists in those who look after the patients with renal failure, may seem a simple task to those 
protagonists of transplantation outside the profession. But it has turned out to be the most difficult and delicate task and will require years of carefully applied effort to achieve. It is a problem which regrettably cannot be resolved by anything as simple as altering the Human Tissue Act.

\section{References}

${ }^{1}$ Kennedy, I (1979). The donation and transplantation of kidneys: should the law be changed ? fournal of medical ethics, 5, 13-2I.
${ }^{2}$ The Human Tissue Act (196r). HMSO, London.

${ }^{3}$ Tovey, G. Personal communication.

${ }^{4}$ Department of Health and Social Security (1975). Guidance circular to NHS authorities on the $\Rightarrow$ Human Tissue Act, I96I. HSC (IS) I56.

${ }^{5}$ Advisory group on transplantation problems (I969). Advice on the question of amending the Human Tissue Act I96I (Cmnd 4106). HMSO London.

${ }^{6}$ Conference of Royal Colleges and Faculties of the $\mathbb{D}$ United Kingdom (1976). Diagnosis of brain death. Lancet, ii, 1060-1070.

'Sells, R A (1979). Live organs from dead people. $\vec{\circ}$ fournal of the royal society of medicine, 72, I09-II I. 